\title{
Adolescent and Young Adult Colorectal Cancer
}

Joleen M. Hubbard, MD, and Axel Grothey, MD

\begin{abstract}
Although the overall incidence of colorectal cancer (CRC) in adolescents and young adults (AYAs) is low, it has seen an increase over the past 2 to 3 decades, which contrasts with the trend of decreased incidence in the older population. This phenomenon is conceivably caused by a lack of routine CRC screening in the young population and lifestyle issues, including the obesity epidemic and dietary factors. Hereditary genetic syndromes (eg, familial adenomatous polyposis and hereditary nonpolyposis colorectal cancer syndrome) and known predisposing medical conditions (eg, inflammatory bowel disease) account for only a minority of CRC cases in AYA. Younger patients with CRC commonly present with more advanced disease at diagnosis and exhibit specific molecular and clinical characteristics associated with a distinct biologic phenotype of CRC compared with older individuals. Matched for stage, however, the prognosis of patients with young-onset CRC is similar to or better than that for older patients. A surprising paucity of data exists on outcomes associated with modern systemic cytotoxic and biologic therapy specifically in young patients with CRC. The toxicity pattern of these treatments, however, differs between young and older patients, partly because of the lower rate of pertinent comorbidities in younger adults. Issues regarding surgical management in the setting of hereditary syndromes and fertility preservation while on therapy are of particular importance to the younger patient population. Future studies should seek to increase understanding of the distinct tumor biology of AYA patients with CRC and the consequences of treatment interventions to optimize outcomes for this population. (JNCCN 2013;11:1219-1225)
\end{abstract}

From the Division of Medical Oncology, Mayo Clinic, Rochester, Minnesota.

Submitted March 4, 2013; accepted for publication May 24, 2013. The authors have disclosed that they have no financial interests, arrangements, affiliations, or commercial interests with the manufacturers of any products discussed in this article or their competitors.

Correspondence: Joleen M. Hubbard, MD, Division of Medical Oncology, Mayo Clinic, 200 First St SW, Rochester MN 55905.

E-mail: hubbard.joleen@mayo.edu

\section{Incidence of Colorectal Cancer in Adolescents and Young Adults}

The incidence of colorectal cancer (CRC) in young adults is relatively low. CRC is typically a disease of older adults, with the average age of colon cancer diagnosis approaching 70 years. The likelihood of patients younger than 40 years developing $\mathrm{CRC}$ is approximately $1: 1200$, compared with $1: 25$ for persons older than 70 years. ${ }^{1} \mathrm{CRC}$ is the third leading cause of cancer-related death among 20 to 39 year olds, behind leukemia and brain/nervous system cancers. The incidence of CRC in patients younger than 20 years is extremely low, approximately $0.03 \%$, based on SEER data. ${ }^{2}$

Although the incidence of CRC is decreasing in the older adult population, several epidemiology studies over the past decade have reported an increase among young adults. ${ }^{3-5}$ A SEER database analysis found a rate of 2.1 per 100,000 persons of colon cancer and 1.4 per 100,000 persons of rectal cancer among 20 to 40 years olds. ${ }^{4}$ The study also noted a $17 \%$ increase in the incidence of colon cancer and a $75 \%$ increase in rectal cancer among 20 to 40 year olds from 1973 through 1999.

A more recent SEER database study evaluating the incidence of CRC among 20 to 49 year olds from 1992 through 2005 found an increase of $1.5 \%$ in men and $1.6 \%$ in women per 100,000 young persons. ${ }^{5}$ Rates increased for every age decade examined (20-29, 30-39, and $40-49$ years), particularly in the youngest individuals (20-29 years), in whom incidence increased $5.2 \%$ in men and $5.6 \%$ in women per year over the 13 -year period. The increase was primarily driven by left-sided tumors, especially rectal cancers. This is in stark contrast to the overall trend in CRC incidence, which declined by $2.6 \%$ for men and $2.1 \%$ for women from 1998 to 2009, largely attributed to be an effect of CRC screening. ${ }^{3}$ 


\section{Etiology}

The exact cause for this alarming trend in young adults is unclear, but has largely been attributed to dietary factors and the rising rate of obesity among young Americans. ${ }^{5}$ Most CRC cases in young adults seem to be sporadic. A systemic review of the literature on young adults with CRC revealed that only $16 \%$ had a documented predisposing factor, such as inflammatory bowel disease (ulcerative colitis, Crohn disease, and regional enteritis), familial adenomatous polyposis (FAP), or hereditary nonpolyposis colorectal cancer (HNPCC) syndrome, and $22 \%$ had family history of CRC. ${ }^{6}$

The 2 major known familial syndromes associated with CRC in young adults are HNPCC (or Lynch syndrome) and FAP. Both of these genetic disorders demonstrate autosomal dominant inheritance and constitute $2.0 \%$ and $0.1 \%$ to $1.0 \%$ of all adult cases of CRC, respectively. ${ }^{7}$ It is unusual for patients with FAP to develop carcinoma before the third decade: $7 \%$ are diagnosed by age 20 years, and $15 \%$ by age 25 years. HNPCC is believed to be the cause of up to $10 \%$ of cases occurring before 50 years of age, with CRC diagnoses usually in the 40 s. $^{8}$ Genetic predispositions for CRC are summarized in Table 1.

HNPCC is caused by germline mutations in 1 of 4 mismatch repair (MMR) genes: MLH1, MSH2, MSH6, and PMS2. Ninety percent of mutations affect MLH1 or MSH2, whereas mutations in PMS2 are the most infrequent. The biologic consequences of the mutation differ between the affected genes. The age-dependent risk for developing CRC varies and is higher for mutations in MLH1 and MSH2 than MSH6 (Figure 1). ${ }^{9}$ By age 40 years, $6 \%$ and $8 \%$ of patients with mutations in MLH1 and MSH2, respectively, will have been diagnosed with CRC, compared with only $1 \%$ of patients with mutated MSH6. In addition, patients with mutations in MSH6 are unlikely to develop other HNPCC-associated cancers, such as ovarian, stomach, urothelial, small bowel, and biliary cancers.

\section{Presentation}

Because patients younger than 50 years without a clear family history of CRC, polyps, or known genetic predisposition do not fall under the current guidelines for screening, most $(>80 \%)$ are diagnosed with symptomatic disease. ${ }^{6,10,11}$ Presenting symptoms are typically related to the site of the bowel lesion, and younger patients more frequently show left-sided tumors. In a systematic review, 22\% of patients younger than 50 years presented with lesions in the ascending colon, $11 \%$ in the transverse colon, $13 \%$ in the descending colon, and $54 \%$ in the sigmoid and rectum. ${ }^{6}$ Therefore, in addition to general symptoms from colon cancer such as abdominal pain, fatigue, and weight loss, younger patients are more likely to present with symptoms associated with a left-sided lesion, including rectal bleeding and altered bowel pattern. ${ }^{12}$

A large retrospective analysis identified 1025 patients aged 50 years and younger diagnosed with CRC seen at the Mayo Clinic between 1976 and 2002, without established risk factors for CRC, including inflammatory bowel disease, polyposis syndromes, or a known genetic predisposition. ${ }^{10}$ The mean age at presentation was 42.4 years, and $86 \%$ of patients were symptomatic at diagnosis. The most common initial symptoms were rectal bleeding $(51 \%)$, change in bowel habits $(18 \%)$, abdominal pain (32\%), weight loss (13\%), nausea/vomiting (7\%), and melena (2\%).

Younger patients commonly experience a delay in diagnosis, sometimes exceeding 6 months, ${ }^{6,12}$ possibly leading to more findings of advanced disease at presentation compared with older patients. In one population-based study comparing CRC in 20 to 40 year olds versus 60 to 80 year olds, the stage distribution was $10.6 \%$ versus $18.6 \%$ for stage I; $23.0 \%$ versus $29.0 \%$ for stage II; $31.5 \%$ versus $22.8 \%$ for stage III; and $24.5 \%$ versus $17.3 \%$ for stage IV, respectively. ${ }^{6}$ These findings are concordant with those of other studies of younger patients showing more advanced disease at presentation. . $^{12,13}$

A host of issues likely contributing to the delay in diagnosis of younger adults with colon cancer was summarized by Bleyer et $\mathrm{al}^{14}$ in 2006 . Both physicians and young adult patients are less likely to attribute symptoms to an underlying malignancy. In addition, the health care system is underused by adolescents and young adults (AYAs) because of several factors, including lack of health care insurance. However, the differences in stage presentation between younger and older adults may also be related to differences in the biology of colon cancer in these populations. 
AYA Colorectal Cancer

\begin{tabular}{|c|c|c|c|c|c|}
\hline $\begin{array}{l}\text { Genetic } \\
\text { Syndrome }\end{array}$ & Mutation & Frequency & Risk of CRC & $\begin{array}{l}\text { Median Age of } \\
\text { CRC Presentation (y) }\end{array}$ & $\begin{array}{l}\text { Clinical } \\
\text { Presentation }\end{array}$ \\
\hline \multirow[t]{2}{*}{ FAP } & \multirow[t]{2}{*}{$\begin{array}{l}\text { APC gene on } \\
\text { chromosome } 5 q 21 \text {, } \\
\text { autosomal dominant }\end{array}$} & \multirow[t]{2}{*}{$\begin{array}{l}1 \%-2 \% \text { of all } \\
\text { CRC, mutation } \\
\text { in } 1: 7,000- \\
22,000\end{array}$} & \multirow[t]{2}{*}{$\begin{array}{l}90 \% \text { by age } \\
45 \mathrm{y}\end{array}$} & \multirow[t]{2}{*}{39} & $\begin{array}{l}\text { Multiple ( }>100) \\
\text { adenomatous polyps } \\
\text { in the colon } \\
\text { and rectum } \\
\text { developing after the } \\
\text { first decade of life }\end{array}$ \\
\hline & & & & & $\begin{array}{l}\text { Multiple clinical } \\
\text { variations with } \\
\text { extracolonic tumors } \\
\text { and attenuated } \\
\text { forms }\end{array}$ \\
\hline \multirow{3}{*}{$\begin{array}{l}\text { Hereditary } \\
\text { nonpolyposis } \\
\text { CRC (Lynch } \\
\text { syndrome) }\end{array}$} & \multirow{3}{*}{$\begin{array}{l}\text { Mismatch repair } \\
\text { enzyme genes (MLH1, } \\
\text { MSH2, MSH6, and } \\
\text { PMS2), autosomal } \\
\text { dominant }\end{array}$} & \multirow{3}{*}{$\begin{array}{l}2 \%-5 \% \text { of all } \\
\text { CRC }\end{array}$} & \multirow{3}{*}{$\begin{array}{l}40 \%-80 \% \text { by } \\
\text { age } 75 y\end{array}$} & \multirow[t]{3}{*}{44} & MSI-H phenotype \\
\hline & & & & & $\begin{array}{l}\text { Various extracolonic } \\
\text { cancers common }\end{array}$ \\
\hline & & & & & $\begin{array}{l}\text { Amsterdam and } \\
\text { Bethesda guidelines } \\
\text { for clinical diagnosis }\end{array}$ \\
\hline $\begin{array}{l}\text { MYH-associated } \\
\text { polyposis }\end{array}$ & $\begin{array}{l}\text { MYH gene, } \\
\text { autosomal recessive }\end{array}$ & $\begin{array}{l}1 \% \text { of all CRC, } \\
1 \%-2 \% \text { of } \\
\text { population } \\
\text { carry } M Y H \\
\text { mutation }\end{array}$ & $\begin{array}{l}35 \%-53 \% \text { in } \\
\text { lifespan }\end{array}$ & $35-45$ & $\begin{array}{l}\text { Broad clinical } \\
\text { spectrum sometimes } \\
\text { resembling } \\
\text { attenuated FAP }\end{array}$ \\
\hline \multirow[t]{3}{*}{$\begin{array}{l}\text { Peutz-Jeghers } \\
\text { syndrome }\end{array}$} & \multirow{3}{*}{$\begin{array}{l}\text { STK11 gene at } \\
\text { chromosome 19p13.3, } \\
\text { autosomal dominant }\end{array}$} & \multirow{3}{*}{$\begin{array}{l}<1 \% \text { of all CRC, } \\
\text { mutation in } \\
1: 25,000- \\
300,000\end{array}$} & \multirow[t]{3}{*}{$\begin{array}{l}39 \% \text { by age } \\
70 y\end{array}$} & \multirow[t]{3}{*}{60} & $\begin{array}{l}\text { Extracolonic cancers } \\
\text { common }\end{array}$ \\
\hline & & & & & $\begin{array}{l}\text { Melanocytic macules } \\
\text { on lips, and perioral } \\
\text { and buccal regions }\end{array}$ \\
\hline & & & & & $\begin{array}{l}\text { Multiple GI } \\
\text { hamartomatous and } \\
\text { adenomatous polyps }\end{array}$ \\
\hline $\begin{array}{l}\text { Juvenile } \\
\text { polyposis } \\
\text { syndrome }\end{array}$ & $\begin{array}{l}\text { MADH4 (SMAD4I } \\
\text { DPC4) gene at } \\
\text { chromosome } 18 \mathrm{q} 21 \\
(15 \%-20 \%) \text {; or } \\
\text { bone morphogenic } \\
\text { protein receptor } \\
1 \mathrm{~A}(B M P R 1 A) \text { gene } \\
\text { at chromosome } \\
10 \mathrm{q} 22(25 \%-40 \%) ; \\
\text { autosomal dominant }\end{array}$ & $<1 \%$ of all CRC & $\begin{array}{l}17 \%-68 \% \text { by } \\
\text { age } 60 \text { y }\end{array}$ & $35-45$ & $\begin{array}{l}\text { Hamartomatous } \\
\text { polyposis } \\
\text { throughout the GI } \\
\text { tract, can present } \\
\text { with diarrhea, GI } \\
\text { tract hemorrhage, } \\
\text { and protein-losing } \\
\text { enteropathy }\end{array}$ \\
\hline
\end{tabular}

Abbreviations: CRC, colorectal cancer; FAP, familial adenomatous polyposis; GI, gastrointestinal, MSI-H, higher rate of microsatellite instability.

\section{Tumor Biology}

Multiple studies have shown that the biologic phenotype of CRC in young adults differs from that in older adults. ${ }^{15}$ As expected, a higher rate of microsatellite instability (MSI-H) is found among younger patients. The largest series $(n=607)$ by Gryfe et $\mathrm{al}^{16}$ found a $17 \%$ rate of MSI-H tumors in patients younger than 50 years. Multiple case series involving small numbers of the youngest patients with colon cancer (including children and adolescents) report MSI-H rates ranging from $46 \%$ to $73 \%$, with rates trending higher as the age of the study population decreases. ${ }^{17-21}$

Most MSI-H tumors in young adults are caused by a sporadic mutation, or are from hypermethylation of one of the MMR genes promoter regions, rather than related to a germline mutation. ${ }^{22} \mathrm{MSI}-\mathrm{H}$ tumors are associated with a better overall prognosis in the overall population, and in young adults. ${ }^{16,23}$ In contrast to microsatellite stable or low tumors 


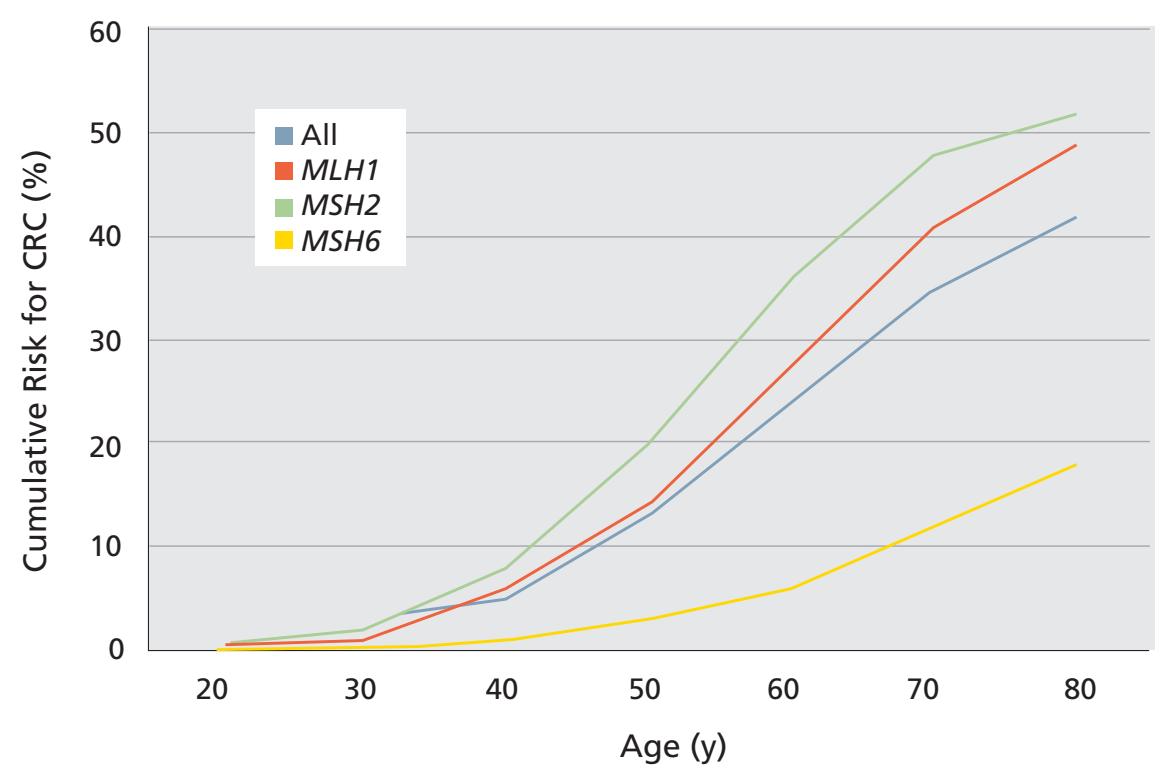

Figure 1 Age-dependent risk for developing colorectal cancer (CRC) according to mutation for patients with hereditary nonpolyposis colorectal cancer.

Data from Bonadona V, Bonaiti B, Olschwang S, et al. Cancer risks associated with germline mutations in MLH1, MSH2, and MSH6 genes in Lynch syndrome. JAMA 2011;305:2304-2310.

(MSS/MSI-L) in which BRAF mutation carries a poor prognosis, BRAF mutant status does not carry a poor prognosis in MSI-H cancers. ${ }^{24}$ The higher rates of MSI-H tumors may explain why younger patients have similar or improved survival rates compared with older patients, when matched stage by stage. ${ }^{6,25}$

A subset of AYAs has more aggressive tumor biology, contributing to poorer outcomes. ${ }^{10,26-29}$ These tumors are more commonly mucin-producing, poorly differentiated, and have signet ring histology. The incidence of mucin-producing tumors is greater in patients younger than 30 years, and the rates increase as the age at diagnosis decreases. ${ }^{17,27}$ A SEER database review of 1736 patients younger than 40 years found that mucinous and poorly differentiated tumors occurred in $21 \%$ and $27 \%$ in young adults, respectively, compared with $12 \%$ and $15 \%$ in older adults. ${ }^{29}$ The underlying mechanisms responsible for the more aggressive tumor biology among young patients remain unknown, but clearly not all of these patients have a readily identifiable genetic predisposition. ${ }^{15,17,30}$

\section{Treatment}

AYA patients have the same standard treatment recommendations for all stages of CRC as older adults. ${ }^{31}$ Standard staging after diagnosis includes a CT scan of the chest, abdomen, and pelvis, and laboratory studies, including a CBC, liver and renal function tests, and carcinoembryonic antigen levels. AYA patients should be assessed for genetic risk factors and referred for genetic testing accordingly. MSI testing should be performed on pathologic specimens to assess for evidence of Lynch syndrome.

\section{Surgical Management}

For AYA patients without a known genetic disposition, segmental colectomy is the standard of care. AYA patients with FAP generally undergo colectomy by the end of their second decade of life. ${ }^{32}$ Surveillance requirements and quality of life issues should be considered when deciding on surgical management of AYA with HNPCC. HNPCC patients who undergo segmental colectomies require frequent colonoscopies; however, those who undergo subtotal or total colectomies with ileorectal anastomosis require less-invasive surveillance methods, such as flexible sigmoidoscopies. ${ }^{33}$ Change in bowel patterns after total colectomies may affect daily activities: $25 \%$ of patients undergoing total colectomy will have 5 or more bowel movements per day, and 30\% will have issues with fecal incontinence. . $^{34,35}$

\section{Adjuvant Therapy for Stage II and III Colon Cancer}

Patients with high-risk stage II and III disease should undergo 6 months of oxaliplatin-based therapy with either modified FOLFOX6 (5-FU, leucovorin, oxali- 
platin) or XELOX (capecitabine, oxaliplatin), which have been shown to improve outcomes in randomized phase III clinical trials. ${ }^{36,37}$ Patients with lowrisk stage II disease should be tested for MSI, and no adjuvant therapy is recommended in those found to have MSI-H tumors.

Younger patients are more likely to receive adjuvant therapy, especially for stage II disease, compared with their older counterparts. Quah et $\mathrm{al}^{11}$ found that $39 \%$ of patients aged 40 years or younger received adjuvant chemotherapy for stage II disease, compared with only $14 \%$ of older patients, even though the clinical and pathologic tumor characteristics were similar. Because younger patients have a higher rate of MSI-H tumors, a larger proportion of younger patients with stage II disease may exist who may not benefit from adjuvant chemotherapy. ${ }^{38,39}$ Given that the overall prognosis for younger patients with colon cancer is similar or improved compared with older patients, this same principle likely applies to younger patients, and adjuvant chemotherapy is unnecessary for younger patients with stage II disease and MSI-H tumors, although this has not been studied in detail.

The benefits of adjuvant therapy in young adults have been studied using the Adjuvant Colon Cancer Endpoints (ACCENT) database. ${ }^{25}$ Of the 33,574 patients from 24 randomized phase III clinical trials, 5817 $(17.3 \%)$ were younger than 50 years, $1758(5.2 \%)$ were younger than 40 years, and $299(0.9 \%)$ were younger than 30 years. Approximately $68 \%$ of patients had stage III disease. In this analysis, younger patients had similar recurrence-free survival (RFS) as older patients. When patients younger than 40 years were compared with those aged 40 years and older, the 5 -year RFS rate was $68.4 \%$ and $66.8 \%$, respectively, with a hazard ratio of 1.02 (95\% CI, 0.94-1.11; $P=.62$ ). Similar findings were seen when the patients were grouped by younger than 50 years and 50 years and older. Disease-free and overall survivals were higher among the younger patients, likely because of the fewer competing causes of death among younger patients.

\section{Metastatic Disease}

Treatment for metastatic CRC includes combination chemotherapy (oxaliplatin and/or irinotecan with a fluoropyrimidine) plus a biologic agent (bevacizumab, cetuximab, and panitumumab). A surprising lack of data exists on survival outcomes in AYAs compared with older adults with current standards of palliative therapy. Most population studies indicate that the AYA population with stage IV disease fares similarly as the older adult population with stage IV disease in terms of survival. Given the adjuvant therapy data, the benefit derived from modern chemotherapy regimens involving irinotecan and oxaliplatin is likely age-independent. More studies are needed regarding the outcomes and tolerance of biologic therapies, including bevacizumab, aflibercept, cetuximab, panitumumab, and regorafenib, in AYA patients. In addition, no detailed data on outcomes after potentially curative metastasectomy are available for young versus old patients with CRC. This highlights the importance of enrolling this patient population in clinical trials.

\section{Treatment Side Effects}

\section{Tolerance of Therapy}

In the aforementioned ACCENT analysis, younger patients tolerated adjuvant treatment as well as, if not slightly better than, older patients. ${ }^{25}$ However, younger patients likely have a different side effect profile than older patients. Although younger patients had a significantly lower incidence of grade $3+$ leukopenia and stomatitis, they tended to have more grade $3+$ nausea and vomiting. In younger patients, the aggressive use of antiemetics may improve treatment tolerability and compliance, and thereby completion of the recommended therapy.

\section{Impact of CRC Therapy on Fertility}

The effects of oxaliplatin, irinotecan, and biologic agents on fertility in men and women are largely unknown. 5-FU is believed to cause a temporary reduction in sperm count for men and to have a low risk for causing amenorrhea in women. ${ }^{40}$ Among 50 women with gastrointestinal cancers who responded to a reproductive health survey (no details on specific treatment regimen provided), infertility increased from $15 \%$ to $30 \%$ as age increased from 18 to 40 years. ${ }^{41}$ Preclinical studies suggest oxaliplatin may have moderate gonadal toxicity, but the long-term effects are unknown. ${ }^{42}$ Depending on the patient's desire to have children and the clinical situation, potential risk for toxicity and fertility preservation options, including sperm banking for men and oocyte/embryo cryopreservation for women, should be discussed with all AYA patients. ${ }^{40}$ 


\section{Survival and Prognosis}

Previously, younger patients were believed to always have more aggressive disease and worse prognosis than older adults. ${ }^{6}$ However, when matched for stage, survival rates seem to be similar or better for young adults than for older adults. ${ }^{6,11,43}$ A large population-based study using the SEER database evaluated 5-year CRC-specific survival outcomes in 1334 patients aged 20 to 40 years compared with 46,457 patients aged 60 to 80 years. ${ }^{43}$ Despite the higher rates of stage III or IV disease and poor tumor differentiation, younger patients had an equivalent, and in some stages better, prognosis than older patients. For younger versus older patients, the 5 -year stagespecific survival was $93.3 \%$ versus $94.9 \%$ ( $P=$ not significant) for stage I disease, $88.6 \%$ versus $82.7 \%$ $(P=.01)$ for stage II disease, $58.9 \%$ versus $57.2 \%(P=$ not significant) for stage III disease, and $18.1 \%$ versus $6.2 \%(P<.001)$ for stage IV disease, respectively.

Most patients studied in the young adult literature were ages 20 to 50 years, and little is known regarding the survival of adolescents treated with the current multidisciplinary approach to CRC. Children and adolescents diagnosed with CRC have been reported to have a very poor prognosis. ${ }^{2,26,30,44}$ However, much of the literature on survival in adolescents consists of small case series, which is not surprising given the rarity of $\mathrm{CRC}$ in this population. In addition, most of the reports on the youngest patients with CRC are from before the introduction of new standards of care, including oxaliplatin-based regimens, adequate nodal dissection, and biologic agents.

The largest series of pediatric/adolescent cases was a SEER database study in which the features and survival outcomes of 159 patients from 1973 to 2005 were compared with those of adults. ${ }^{2}$ This study confirms the poorer survival of children and adolescents compared with adults: the 5-year survival rates were $40 \%$ and $60 \%$, respectively, and the 10-year survival rates were $31 \%$ and $54 \%$, respectively $(P<.001)$. Interestingly, although survival outcomes improved over that period for adults, no survival improvements were seen in children and adolescents.

\section{Conclusions}

Although the rising incidence of CRC in AYAs in the past decades is well documented, understanding of epidemiologic, genetic, and biologic factors leading to this increase is incomplete. In addition, CRC in AYA patients exhibits a clinical, histologic, and molecular phenotype, which sets it apart from cancers diagnosed in older individuals for yet unknown reasons. The lack of detailed information on outcomes associated with modern cytotoxic and biologic therapies in young patients with CRC warrants refined retrospective and prospective analyses of treatment effects in this specific population in clinical trials to elucidate whether the characteristic biologic phenotype and molecular alterations found in AYA CRC should lead to specific treatment interventions.

\section{References}

1. Siegel R, Naishadham D, Jemal A. Cancer statistics, 2013. CA Cancer J Clin 2013;63:11-30.

2. Sultan I, Rodriguez-Galindo C, El-Taani H, et al. Distinct features of colorectal cancer in children and adolescents: a populationbased study of 159 cases. Cancer 2010;116:758-765.

3. Merrill RM, Anderson AE. Risk-adjusted colon and rectal cancer incidence rates in the United States. Dis Colon Rectum 2011;54:1301-1306.

4. O'Connell JB, Maggard MA, Liu JH, et al. Rates of colon and rectal cancers are increasing in young adults. Am Surg 2003;69:866-872

5. Siegel RL, Jemal A, Ward EM. Increase in incidence of colorectal cancer among young men and women in the United States. Cancer Epidemiol Biomarkers Prev 2009;18:1695-1698.

6. O'Connell JB, Maggard MA, Livingston EH, Yo CK. Colorectal cancer in the young. Am J Surg 2004;187:343-348.

7. Durno $\mathrm{CA}$, Gallinger $\mathrm{S}$. Genetic predisposition to colorectal cancer: new pieces in the pediatric puzzle. J Pediatr Gastroenterol Nutr 2006;43:5-15.

8. Aaltonen LA, Salovaara R, Kristo P, et al. Incidence of hereditary nonpolyposis colorectal cancer and the feasibility of molecular screening for the disease. N Engl J Med 1998;338:1481-1487.

9. Bonadona $\mathrm{V}$, Bonaiti $\mathrm{B}, \mathrm{Olschwang} \mathrm{S}$, et al. Cancer risks associated with germline mutations in MLH1, MSH2, and MSH6 genes in Lynch syndrome. JAMA 2011;305:2304-2310.

10. Dozois EJ, Boardman LA, Suwanthanma W, et al. Young-onset colorectal cancer in patients with no known genetic predisposition: can we increase early recognition and improve outcome? Medicine (Baltimore) 2008;87:259-263.

11. Quah HM, Joseph R, Schrag D, et al. Young age influences treatment but not outcome of colon cancer. Ann Surg Oncol 2007;14:2759-2765.

12. Taggarshe $\mathrm{D}$, Rehil N, Sharma $\mathrm{S}$, et al. Colorectal cancer: are the "young" being overlooked? Am J Surg 2013;205:312-316.

13. Bleyer A. Young adult oncology: the patients and their survival challenges. CA Cancer J Clin 2007;57:242-255.

14. Bleyer A, Budd T, Montello M. Adolescents and young adults with cancer: the scope of the problem and criticality of clinical trials. Cancer 2006;107:1645-1655.

15. Bleyer A, Barr R, Hayes-Lattin B, et al. The distinctive biology of cancer in adolescents and young adults. Nature Rev Cancer 
AYA Colorectal Cancer

\section{8;8:288-298.}

16. Gryfe R, Kim H, Hsieh ET, et al. Tumor microsatellite instability and clinical outcome in young patients with colorectal cancer. $\mathrm{N}$ Engl J Med 2000;342:69-77.

17. Datta RV, LaQuaglia MP, Paty PB. Genetic and phenotypic correlates of colorectal cancer in young patients. $\mathrm{N}$ Engl J Med 2000;342:137-138.

18. Durno C, Aronson M, Bapat B, et al. Family history and molecular features of children, adolescents, and young adults with colorectal carcinoma. Gut 2005;54:1146-1150.

19. Liu B, Farrington SM, Petersen GM, et al. Genetic instability occurs in the majority of young patients with colorectal cancer. Nat Med 1995;1:348-352.

20. Lukish JR, Muro K, DeNobile J, et al. Prognostic significance of DNA replication errors in young patients with colorectal cancer. Ann Surg 1998;227:51-56.

21. Pucciarelli S, Agostini M, Viel A, et al. Early-age-at-onset colorectal cancer and microsatellite instability as markers of hereditary nonpolyposis colorectal cancer. Dis Colon Rectum 2003;46:305-312.

22. Boland CR, Thibodeau SN, Hamilton SR, et al. A National Cancer Institute Workshop on microsatellite instability for cancer detection and familial predisposition: development of international criteria for the determination of microsatellite instability in colorectal cancer. Cancer Res 1998;58:5248-5257.

23. Popat S, Hubner R, Houlston RS. Systematic review of microsatellite instability and colorectal cancer prognosis. J Clin Oncol 2005;23:609-618.

24. Roth AD, Tejpar S, Delorenzi M, et al. Prognostic role of KRAS and BRAF in stage II and III resected colon cancer: results of the translational study on the PETACC-3, EORTC 40993, SAKK 6000 trial. J Clin Oncol 2010;28:466-474.

25. Hubbard J, Thomas DM, Yothers G, et al. Benefits and adverse events in younger versus older patients receiving adjuvant chemotherapy for colon cancer: findings from the Adjuvant Colon Cancer Endpoints data set. J Clin Oncol 2012;30:2334-2339.

26. LaQuaglia MP, Heller G, Filippa DA, et al. Prognostic factors and outcome in patients 21 years and under with colorectal carcinoma. J Pediatr Surg 1992;27:1085-1089; discussion 1089-1090.

27. Chiang JM, Chen MC, Changchien CR, et al. Favorable influence of age on tumor characteristics of sporadic colorectal adenocarcinoma: patients 30 years of age or younger may be a distinct patient group. Dis Colon Rectum 2003;46:904-910.

28. Tricoli JV, Seibel NL, Blair DG, et al. Unique characteristics of adolescent and young adult acute lymphoblastic leukemia, breast cancer, and colon cancer. J Natl Cancer Inst 2011;103:628-635.

29. Griffin PM, Liff JM, Greenberg RS, Clark WS. Adenocarcinomas of the colon and rectum in persons under 40 years old. A populationbased study. Gastroenterology 1991;100:1033-1040.

30. Hill DA, Furman WL, Billups CA, et al. Colorectal carcinoma in childhood and adolescence: a clinicopathologic review. J Clin
Oncol 2007;25:5808-5814.

31. Coccia PF, Altman J, Bhatia S, et al. NCCN Clinical Practice Guidelines in Oncology for Adolescent and Young Adult Oncology, version 1.2012. Available at: NCCN.org. Accessed September 17, 2013.

32. Smith KD, Rodriguez-Bigas MA. Role of surgery in familial adenomatous polyposis and hereditary nonpolyposis colorectal cancer (Lynch syndrome). Surg Oncol Clin N Am 2009;18:705715.

33. Puts MT, Visser M, Twisk JW, et al. Endocrine and inflammatory markers as predictors of frailty. Clin Endocrinol (Oxf) 2005;63:403411.

34. Soravia C, Klein L, Berk T, et al. Comparison of ileal pouch-anal anastomosis and ileorectal anastomosis in patients with familial adenomatous polyposis. Dis Colon Rectum 1999;42:1028-1033.

35. Aziz $\mathrm{O}$, Athanasiou $\mathrm{T}$, Fazio VW, et al. Meta-analysis of observational studies of ileorectal versus ileal pouch-anal anastomosis for familial adenomatous polyposis. Br J Surg 2006;93:407-417.

36. Andre $\mathrm{T}$, Boni $\mathrm{C}$, Navarro $\mathrm{M}$, et al. Improved overall survival with oxaliplatin, fluorouracil, and leucovorin as adjuvant treatment in stage II or III colon cancer in the MOSAIC trial. J Clin Oncol 2009;27:3109-3116.

37. Haller DG, Tabernero J, Maroun J, et al. Capecitabine plus oxaliplatin compared with fluorouracil and folinic acid as adjuvant therapy for stage III colon cancer. J Clin Oncol 2011;29:14651471.

38. Ribic CM, Sargent DJ, Moore MJ, et al. Tumor microsatelliteinstability status as a predictor of benefit from fluorouracilbased adjuvant chemotherapy for colon cancer. N Engl J Med 2003;349:247-257.

39. Sargent DJ, Marsoni S, Monges G, et al. Defective mismatch repair as a predictive marker for lack of efficacy of fluorouracil-based adjuvant therapy in colon cancer. J Clin Oncol 2010;28:32193226.

40. Lee SJ, Schover LR, Partridge AH, et al. American Society of Clinical Oncology recommendations on fertility preservation in cancer patients. J Clin Oncol 2006;24:2917-2931.

41. Letourneau JM, Ebbel EE, Katz PP, et al. Acute ovarian failure underestimates age-specific reproductive impairment for young women undergoing chemotherapy for cancer. Cancer 2012;118:1933-1939.

42. Marhhom E, Cohen I. Fertility preservation options for women with malignancies. Obstet Gynecol Surv 2007;62:58-72.

43. O'Connell JB, Maggard MA, Liu JH, et al. Do young colon cancer patients have worse outcomes? World J Surg 2004;28:558-562.

44. Ferrari A, Rognone A, Casanova M, et al. Colorectal carcinoma in children and adolescents: the experience of the Istituto Nazionale Tumori of Milan, Italy. Pediatr Blood Cancer 2008;50:588-593. 